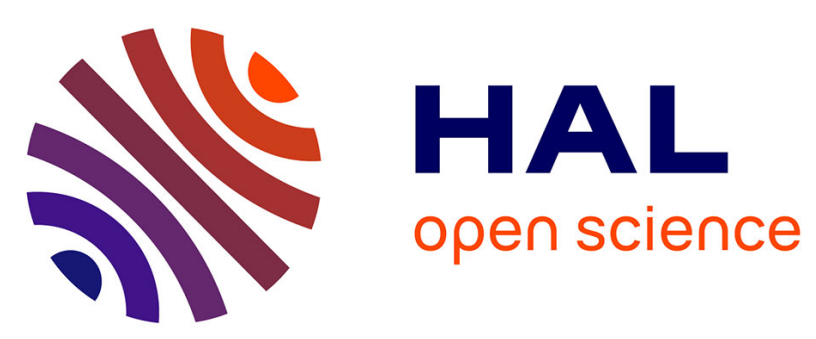

\title{
Differentiation and Customer Decoupling Points: Key Value Enablers for Mass Customization
}

\author{
Joanna Daaboul, Catherine Da Cunha
}

\section{To cite this version:}

Joanna Daaboul, Catherine Da Cunha. Differentiation and Customer Decoupling Points: Key Value Enablers for Mass Customization. IFIP International Conference on Advances in Production Management Systems (APMS), Sep 2014, Ajaccio, France. pp.43-50, 10.1007/978-3-662-44733-8_6 . hal01387145

\section{HAL Id: hal-01387145 \\ https://inria.hal.science/hal-01387145}

Submitted on 25 Oct 2016

HAL is a multi-disciplinary open access archive for the deposit and dissemination of scientific research documents, whether they are published or not. The documents may come from teaching and research institutions in France or abroad, or from public or private research centers.
L'archive ouverte pluridisciplinaire HAL, est destinée au dépôt et à la diffusion de documents scientifiques de niveau recherche, publiés ou non, émanant des établissements d'enseignement et de recherche français ou étrangers, des laboratoires publics ou privés. 


\title{
Differentiation and Customer decoupling points: Key value enablers for mass customization
}

\author{
Joanna Daaboul ${ }^{1}$, Catherine da Cunha ${ }^{2}$ \\ ${ }^{1}$ Laboratoire Roberval UMR CNRS 7337, Department of Mechanical Systems Engineering, \\ UTC - Université de Technologie de Compiègne, Compiègne, France \\ ${ }^{2}$ LUNAM UNIVERSITE, ECOLE CENTRALE DE NANTES - IRCCYN UMR CNRS 6597 - \\ 1 Rue de la Noë, Nantes, France
}

\begin{abstract}
Mass customization draws a twofold benefit: cost reduction, inherited from mass production techniques, and good response to customers' requirements, inherited from customization. Two main decisions, relevant to design and manufacturing, are required for proper implementation of mass customization. Firstly, product features should be split between standard and customizable ones. This will position the differentiation points. Secondly, processes should be split between Make-to-Stock and Make-to-order. This will position the customer-order decoupling point. The impact of these 2 criteria on enterprise and customer value will be evaluated through the creation of a generic causal diagram. Following, a real case study on ALPINA industries is simulated and analyzed. The computational results highlight the joint impact of the two decisions on the overall performance. Hence, the results advocate that these two levers should then be considered, simultaneously, when implementing mass customization.
\end{abstract}

Keywords: Mass customization, value, decoupling point, differentiation points

\section{Introduction}

Many companies in different fields (Adidas, Nike, DELL, Woonio for customized furniture, Spreadshirt for customized shirts, Louis Vuitton, Motorola, BMW etc.) implemented Mass Customization (MC). It enables to benefit both from costs reduction (mass production) and good response to customers' requirements (customization). Even though MC was the center of many research projects (trying to better identify this strategy, understand its enablers and how it can be implemented successfully), many questions remained unanswered. There are two main decisions when implementing MC:

1. What customization to offer to the customer: which components of the product will be standard and which will be customized, thus where to position the product differentiation points (PDP). 
2. How to produce a mass customized product: which processes will be Make-toStock (MTS) and which will be Make-to-order (MTO), thus where to position the customer-order-decoupling-point (CODP).

Until now those two questions were often answered separately. This paper advocates that PDP and CODP should be considered simultaneously when defining the best MC customization strategy for a company. The paper is organized as follows: section 2 presents a definition and a literature review for the three main concepts: value, PDP, and CODP. Section three describes the methodology used. Section 4 presents a case study and finally a conclusion in section 5 on the opportunities for MC.

\section{$2 \quad$ Literature review}

\subsection{Value}

Based on a literature review combined with an empirical study, Daaboul et al. (2012b) concluded that value can be identified as "the amount of satisfaction created, by fulfilling a certain physical, biological, or psychological need of a beneficiary party". Many criteria (such as cost, delay, perceived quality, and perceived price) influence it. It can be objective or subjective. It depends on circumstances and is related to the specific goals of the beneficiary party. Different performance indicators are used as its measurement. Value has different beneficiary parties. Those can be the customer, suppliers, enterprise, stakeholders, etc. All those form a value network which is a group of partners collaborating together in order to generate value. A value network, unlike a value chain, is not a linear sequential order of activities transforming materials into products. It allows the consideration of the interactions between the different activities, and relies on the definition of value being multicriteria, subjective and with different beneficiary parties (Daaboul et al., 2014). For the enterprise, the financial value (its objective value) is measured by its profit. Its subjective value is measured by its image, customer loyalty, ranking among completion, etc. For the customer, value is purely subjective. It is measured by dividing the perceived quality (of the product and related services) to the perceived price.

\subsection{Product Differentiation Point (PDP)}

The product differentiation point denominates an operation that transforms a product common to all the products of the same family to a customized or personalized product (finished or not). This transformation can be done by the adjunction of specialized components and/or by the action of a special process. PDP can be multiple, as many attributes can differentiate products among a family. Figure 1 schematizes the multiple product differentiation points that enable obtaining a final product from common inventories. PDPs are not limited to technological products. For instance in the agro- 
food industry, the large variety of formats and/or packaging, which creates customization, compensates the relative simplicity of the product (van Donk 2001).

The choice of PDP encompasses the 2 dimensions of MC optimization: product and process. Product differentiation is either studied on the product portfolio angle (how many different options should be offered) or on the position in the chain angle (should the PDP be moved to the customer: postponement). The differentiation may occur in any attribute of the product including price and localization. A good localization of PDP is closely linked not only to the process used, but also to the information describing the demand (Zhang et al. 2013).

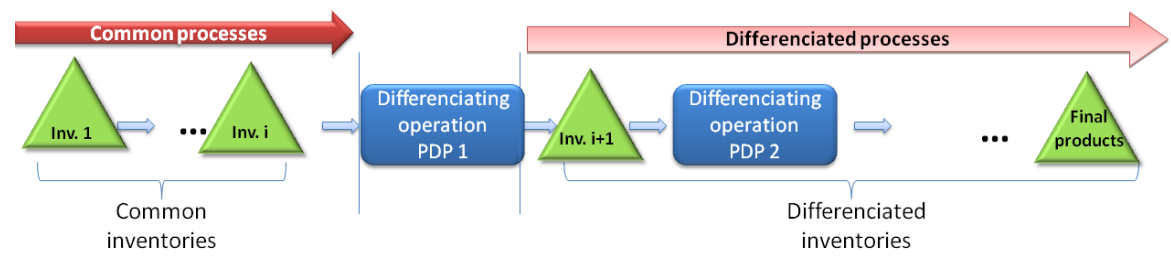

Fig. 1. Multiple PDPs

\subsection{CODP}

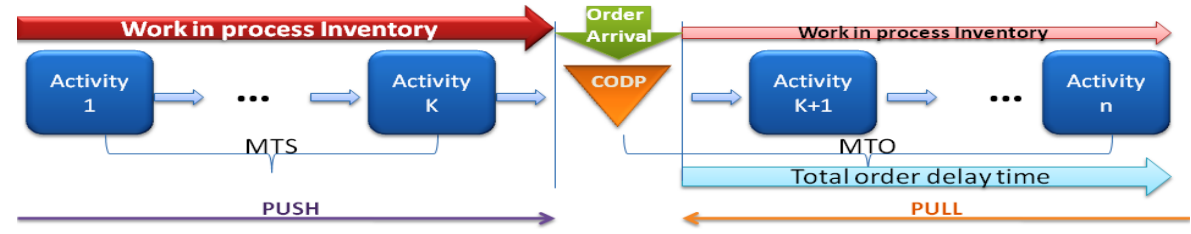

Fig. 2. CODP position

Ji et al. (2007) defined the CODP as "the breaking point between productions for stock based on forecast and customization that responds to customer demand. It is also the breaking point between MTS and MTO, namely, activities before CODP are driven by forecast while activities after CODP are driven by real customer order demand". The CODP position is a main factor in classifying MC systems (Daaboul et al. 2012a). It does not determine what the customization offer is, but influences it, and determines how this offer is being satisfied. According to the literature, the location of the CODP can be at one of the 5 following points: design, production, assembly, distribution, and consumer (Martinez-Olvera and Shunk 2006).

When determining the CODP position (Figure 2), the main factors to consider are: production process, setup time, production technology cost, customer service level, production utilization rate, and the requirements of work in process for storage conditions and time (Ji et al. 2007). Many authors have presented an optimization problem to define the optimal position of the CODP such as Olhager (2003), Ji et al. (2007), Shao and Jia (2008) and Abbey et al. (2013). The CODP position should be determined based on the overall value generated by the system for each beneficiary party 
(e.g. customers, shareholders, company). In fact, the CODP position influences the performance of the network via its impact on costs (cost of resources, cost of materials, inventory cost, production cost, transportation cost), delays (setup time, processing time, delivery delays, order delay time, etc.), and quality (conforming commands, customer perceived quality of the product and the service, etc.). Its position should be optimized by taking into consideration not only capacity constraints, cost and time, but also the product differentiation points and the customization possibilities offered to the customer.

\subsection{Coupled analysis}

The question of PDP and CODP positioning were often considered as exclusive alternatives. Zinn and Bowersox (1988) addressed both questions; naming the point of differentiation "form postponement" and the customer-order-decoupling-point "time postponement". They concluded that product price is the variable that justifies form postponement while uncertainty is determinant for time postponement. Nevertheless in their model form postponement can only occur after the customer order is received. $\mathrm{Su}$ et al (2005) considered form and time postponement as exclusive alternatives. They have concluded that once the number of products increases above some threshold, the time postponement structure is preferred under both performance metrics (cost and waiting time). According to them, form postponement structure is more favorable in the case of higher arrival time and process time variations. Time postponement is more favorable in the case of higher interest rates. Hegde et al (2005) developed a framework to address what degrees of customization to offer. Their results showed that product conformance gradually decreased when the degree of customization exceeded the manufacturing threshold. This paper advocates that the decision on the customization offer should be made simultaneously with the decision on the manufacturing system configuration, and in particular with the CODP determination. Fujita et al. (2012) propose a mathematical model for strategy-level simultaneous design of module commonalization and supply chain configuration. They consider necessary to address both decisions simultaneously.

\section{Methodology}

The developed decision aid system for value networks consists of an evaluation of a strategic decision (such as moving to MC) considering its impact on generated value for all partners. It is based on a what-if analysis and comparison of different possible scenarios. In step 3 of the methodology shown in Figure 3, possible TO-BE scenarios are defined. In our case, a TO-BE scenario consists of a combination of CODP position and PDPs position. This is realized by identifying possible PDP positions, possible CODP positions and then by identifying all possible combination of these positions. Step 4 analyses the results.

A specific library was developed by Daaboul et al. (2013) for discrete event simulation software: Arena (Rockwell Automation). It is intended to model and simulate 
easily and in short time, large and complex value networks. It concentrates on value evaluation. It also permits easy modeling and simulation of different PDPs and CODPs. It is formed of seven modules: order generator, decision activity, trigger, execution activity, partner, variant, and physical flow. The library permits evaluating customer perceived value and value for enterprise.

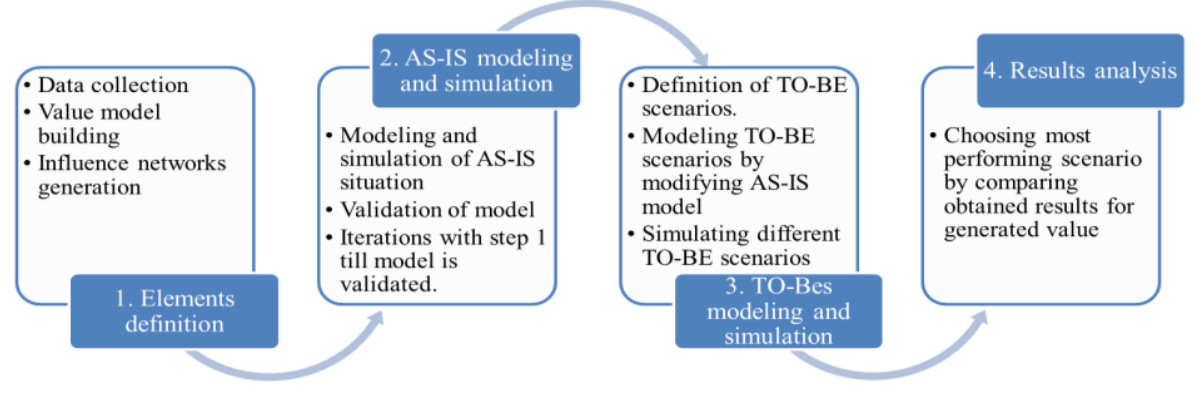

Fig. 3. : Methodology for evaluation of value network evolution

\section{Case study: Alpina (Footwear Industry)}

\subsection{ALPINA}

To challenge the hypothesis that CODP and PDP are linked, a real case was studied. It concerns a shoemaking industry in Slovenia, named Alpina which was founded in 1947. Nowadays, Alpina is a worldwide company with 1800 employees and with production and sales companies in 11 different countries. In 2011 Alpina sold more than 500000 pairs, what means world $n^{\circ} 1$ in production of cross ski country boots with more than $30 \%$ part of the world market.

\subsection{Shoe parts and shoe process}

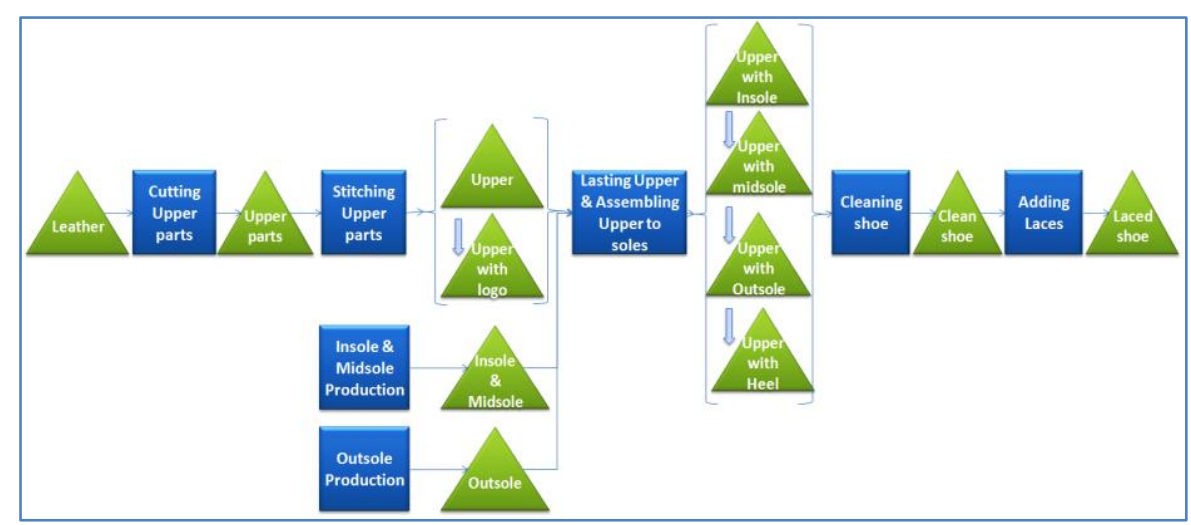

Fig. 4. : Simplified shoe fabrication process 
A shoe is formed essentially of an upper, outsole, insole, midsole, eyelets, buckle, laces, and accessories. After analysis and discussions with Alpina, two possible PDPs were identified. The first PDP is at the laced shoe stage, meaning that the customer can only customize the color of the laces. The second PDP is at the upper stage, meaning that the customer may customize the color of its shoe, the type and color of the outsole, and the laces.

The shoe production process essentially consists of seven main processes: outsole production, insole and midsole production, cutting upper parts, stitching upper parts, lasting upper and assembling it to the soles, cleaning the shoes, and adding laces. This process leads to five possible CODPs (CODP 1 before outsole production, CODP2 before cutting upper parts, CODP3 before stitching upper parts, CODP4 before lasting upper, and CODP5 before adding laces. Figure 4 shows both the process and the shoe parts.

\subsection{Simulation of value network of Alpina}

Needed data (concerning products, processes, supply chain, distributor, suppliers, etc.) were collected from the enterprise using different templates and many interviews with different departments of Alpina. An empirical study realized by Alpina permitted obtaining the perceived quality attributes (fitting, aesthetics, material, thermal comfort, flexibility, weight, stability, breathability, durability and waterproofing, brand name, ecological level, shop assistance, customization time and number of proposed product variants). Thus all needed data for building the value model was provided by the real world. The performance indicators measuring customer value were chosen in coherence with the firm's strategy. Concerning the service related attributes, they are chosen according to (Daaboul et al., 2011).

The value network with PDP 1 and CODP 1 stands for the AS-IS situation. After collecting all needed data, this scenario was simulated and validated by Alpina. After validating the AS-IS scenario (scenario 1), 8 other scenarios were identified. The scenario formed of PDP 2 and CODP 5 is not feasible since it is not possible to have such customization of the shoe and have the customer order decoupling point positioned at the last stage.

\subsection{Results}

The obtained results were validated by Alpina. The results were coherent with other analysis and studies realized at Alpina. As shown in Figure 5, the value for Alpina is higher in the case of PDP at position 1. This is due to the fact that Alpina was not ready to make the necessary changes and investments such as changing its agreements with its suppliers in order to offer MC shoes. Whereas the customer perceived value has a less predictable behavior. It is impacted by many indicators such as product perceived quality, offered customization, and order delay. The results (Figure 5) show that the value for Alpina is higher for PDP1 than PDP2 no matter the position of CODP. The value for Alpina is highest when the CODP is further in the chain 
(CODP5). In addition it reduces dramatically for CODP $1,2,3 \& 4$ compared to CODP5. This is due to:

- An increase in cost of raw material caused by the increase in the required stock for each material.

- Reduced economies of scale as the size of the production batch in the case of MC is equal to 1 .

- An increase in the cost of usage of resources, since the execution time of an activity increased with increasing set-up time.

- A slight increase in transportation costs caused by increased late orders that require faster delivery therefore more expensive.

- A slight increase in turnover. As part of the MC, Alpina estimated a 5\% increase in sales. However, this increase in sales (an increase of 37,559 Euros) was not sufficient to cover the additional costs.

The Pareto Front for Alpina's results was built. It shows the dominating combinations of CODP and PDP.

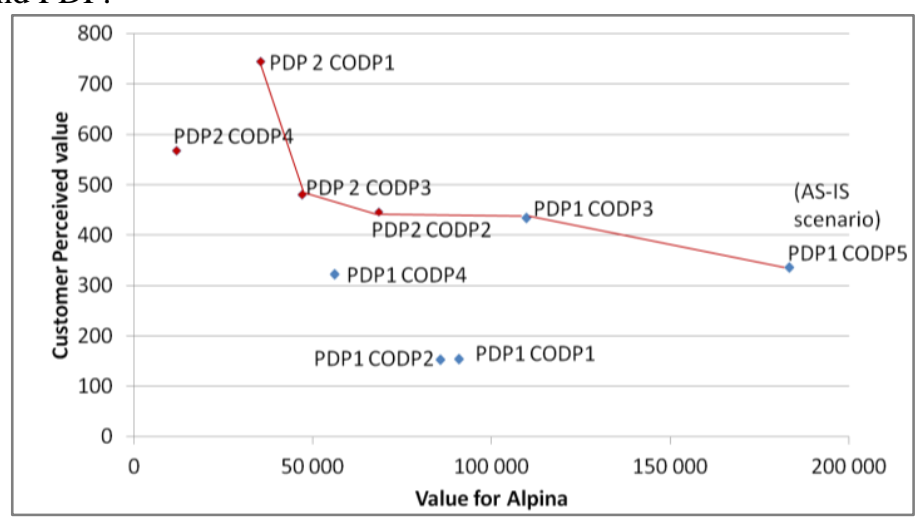

Fig. 5. Scenarios' performance and Pareto front

\section{$5 \quad$ Discussion and conclusion}

The case study validates the adopted framework. The results obtained validate the hypothesis of considering both CODP and PDP positions in defining the best MC strategy for a company. PDP and CODP are the two main acting variables defining the customization strategy. They do not only define the type of MC but influence greatly both customer perceived value and enterprise value. Thus deciding on a MC strategy should be made in light of the influence of those two variables on the value for the different partners. Offering high customization might not always better satisfy the customer.

(Mason-Jones and Towill, 1999) stressed that to maximize competitive opportunity CODP position should be considered jointly with information decoupling point (when information from forecast and market meet). The early usage of distorted information 
could improve capacity management. Hence, future work is needed in order to investigate the joint impact of CODP, PDP and the information decoupling point (IDP).

\section{References}

1. Abbey, J. D., Guide, V. D. R., \& Souza, G. C. (2013). Delayed Differentiation for Multiple Lifecycle Products. Production and Operations Management, 22(3), 588-602.

2. Daaboul, J., Da Cunha, C., Bernard, A., \& Laroche F. (2011). Design for Mass Customization: Product variety vs. Process variety. CIRP Annals, 23(6), 169-174.

3. Daaboul, J., Bernard, A. \& Laroche, F. (2012a). Extended value network modelling and simulation for mass customization implementation. Journal of Intelligent Manufacturing, 23(6), 2427-2439

4. Daaboul, J., Da Cunha, C., Bernard, A., \& Laroche, F. (2012b). Value of personalized products: modelling the customer perception. Proceedings of The 2011 World Conference on Mass Customization, Personalization, and Co-Creation (MCPC 2011). Ed. Chesbrough H. and Piller F., Lulu.com. (Raleigh, NC),ISBN: 978-1-4716-3023-1

5. Daaboul, J., Le Duigou, J., Da Cunha, C., \& Bernard, A. (2013). Value networks: pulling the triggers. A combined approach of modelling and simulation for performance evaluation. International Journal of Computer Integrated Manufacturing. DOI:10.1080/0951192X.2013.834478.

6. Daaboul, J., Castagna, P., Da Cunha, C., \& Bernard, A., 2014. Value network modelling and simulation for strategic analysis: A discrete event simulation approach. International Journal of Production Research.DOI: 10.1080/00207543.2014.886787.

7. Fujita, K., Amaya, H., \& Akai, R. (2012). Mathematical model for simultaneous design of module commonalization and supply chain configuration toward global product family. Journal of Intelligent Manufacturing, 24(5), 991-1004.

8. Hegde, V. G. , Kekre, S., Rajiv, S., \& Tadikamalla, P. R. (2005). Customization : Impact on Product and Process Performance. Production and Operations Management, 14(4), 388-399.

9. Ji, J., Qi, L., \& Gu, Q. (2007). Study on CODP Position of Process Industry Implemented Mass Customization. Systems engineering - Theory and practice, 27(12), 152-157.

10. Martínez-Olvera, C., \& Shunk, D. (2006). Comprehensive framework for the development of a supply chain strategy. International Journal of Production Research, 44(21), 45114528.

11. Mason-Jones, R., \& Towill, D. (1999). Using the information decoupling point to improve supply chain performance. International Journal of Logistics Management, 10(2), 13-26.

12. Olhager, J. (2003). Strategic positioning of the order penetration point. International Journal of Production Economics, 85(3), 319-329.

13. Shao, X.-F., \& Jia, J.-H. (2008).Evaluation of postponement strategies in mass customization with service guarantees. International Journal of Production Research, 46 (1) 153-171.

14. Su, J., Chang, Y_L., \& Ferguson, M. (2005). Evaluation of postponement structures to accommodate mass customization. Journal of Operations Management, 23 (3-4), 305-318.

15. Van Donk, D.P. (2001). Make to stock or make to order: The decoupling point in the food processing industries. International Journal of Production Economics, 69(3), 297-306.

16. Zhang, J., Shou, B., \& Chen, J. (2013). Postponed product differentiation with demand information update. International Journal of Production Economics, 141(2), 529-540.

17. Zinn, W., \& Bowersox, D.J., 1988.Planning physical distribution with the principle of postponement. Journal of Business Logistics, 9(2), 117-136. 